\title{
EL FRAUDE INTELECTUAL. LA COPIA Y EL PLAGIO
}

\author{
Prof. Dr. Miguel Louis Cereceda \\ Defensor de la Universidad de Alicante
}

El fraude intelectual en la Universidad, ya sea en forma de copia o plagio, se puede producir en diferentes ámbitos y es difícil de evitar, pero es un tema que debemos tratar los Defensores/as y Sindics en aras de una mejora de la calidad universitaria.

Si bien es cierto que el estudiante que realiza un fraude de este tipo, ya sea "Copia" o "Plagio" debe ser sancionado, como defensores debemos también evitar los casos en los que se produce abuso de poder, es decir un castigo desproporcionado a la falta cometida.

El problema en mi opinión, esta en como proceder por parte del profesorado cuando detectan un caso de este tipo, ya sea en un examen o en la redacción de un trabajo.

En el caso de la copia la práctica generalizada por parte de profesoras/es es suspender al estudiante, normalmente con un cero. Desde el punto de vista administrativo esto es aplicar una sanción prácticamente de plano (Jiménez Soto, 2009) sin que ello este recogido en el Reglamento de disciplina académica (que sanciona este tipo de faltas con expulsión temporal) y en muy pocas normativas universitarias, por lo que no existe cobertura legal para este tipo de sanción.

El art. 25.1 de la Constitución Española dice: "Nadie podrá ser sancionado por acciones $\mathrm{u}$ omisiones que en el momento de producirse no constituyan delito, falta o infracción administrativa, según la legislación vigente”.

Está claro que esta forma de proceder generalizada debería estar regulada por las universidades para adecuar su actuación a la legalidad (Jiménez Soto, 2009). Por lo tanto nuestra misión en este caso como defensores es promover en nuestras universidades la redacción de un reglamento de disciplina académica que recoja este tipo de sanciones pero a la vez evite los casos de castigo desproporcionado.

Según el Tribunal Constitucional y el Tribunal Supremo, ante un caso de posible copia en un examen, es un hecho objetivo, que sólo puede tener incidencia en la valoración del ejercicio si resulta suficientemente acreditado, sin que basten las meras sospechas o apreciaciones subjetivas de los miembros del órgano de valoración. "Los indicios de la posible 
copia, siempre más de uno, han de estar completamente acreditados de manera directa, no bastando las meras sospechas”. Esto constituye doctrina juridisprudencial.

En cuanto al otro tipo de fraude: el plagio se da en los trabajos de curso, tesis doctorales y publicaciones de todo tipo.

Del latín plagium, el término plagio menciona tanto la acción como el efecto de plagiar. Este verbo, por su parte, hace referencia a copiar obras ajenas, por lo general sin autorización o de manera encubierta (fig. 1).

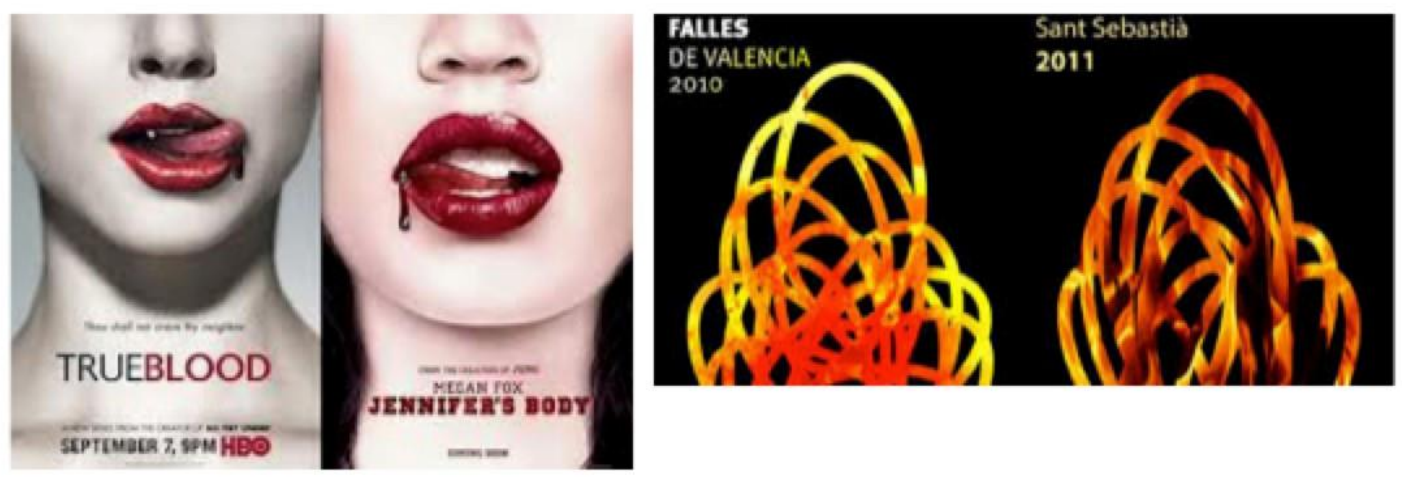

Fig. 1. Ejemplos de plagio en carteles

En el Diccionario de la lengua española de la Real Academia Española se define plagio como la acción de «copiar en lo sustancial obras ajenas, dándolas como propias».1

$\mathrm{Al}$ igual que la Real Academia Española, la Doctrina del Tribunal Supremo entiende por plagio "todo aquello que supone copiar obras ajenas en lo sustancial". Así mismo, amplia la definición del concepto al presentar el plagio "como una actividad material mecanizada, poco creativa y carente de originalidad, aunque aporte cierta manifestación de ingenio". Concluyendo que "el concepto de plagio ha de referirse a las coincidencias estructurales básicas y fundamentales y no a las accesorias, añadidas, superpuestas o modificaciones trascendentales" (STS núm. 12/1995 de 28 de enero).

En definitiva, el plagio es usar el trabajo, las ideas, o las palabras de otra persona como si fueran propias, sin acreditar de manera explícita de donde proviene la información.

Así pues, una persona comete plagio si copia o imita algo que no le pertenece y se hace pasar por el (la) autor(a) de ello. En el caso de documentos escritos, por ejemplo, se tipifica este delito cuando, sin uso de comillas o sin indicar explícitamente el origen, ni citar la fuente original de la información, se incluye una idea, un párrafo o una frase ajenos. 
Es decir, se comete plagio cuando se divulga, publica y reproduce una obra a nombre de un autor distinto del verdadero, atentando a sus derechos morales y patrimoniales, ya que se usurpa su autoría y se defraudan sus intereses económicos.

La información ajena es propiedad de otra persona (como lo es un coche o cualquier otra cosa que poseemos), independientemente de que sea gratis o no, o de la forma en que hayamos accedido a ella (en Internet, una revista, un libro). Nuestras palabras nos pertenecen y no pueden utilizarse sin nuestro permiso. (C. Gómez, 2009).

Por eso, el plagio es una infracción del derecho de autor sobre una obra de cualquier tipo, que se produce mediante la copia de la misma, sin autorización de la persona que la creó o que es dueña o que posee los derechos de dicha obra, y su presentación como obra original.

Básicamente, existen dos formas de plagiar un trabajo: realizar copias ilegítimas de una obra protegida por los derechos de autor o presentar una copia y hacerla pasar por un producto original. Ambas acciones dan derecho a los perjudicados de llevar al infractor a juicio, y las consecuencias suelen consistir en la imposición de distintos tipos de multas y sanciones.

En la Universidad muchos estudiantes se sienten presionados para completar sus trabajos bien y rápidamente. Dada la accesibilidad de las nuevas tecnologías (Internet en particular) pueden realizarlos mediante copia y transcripción de información de otras fuentes y así los entregan a tiempo con poco esfuerzo. Los profesores detectan fácilmente esta forma de actuar, por varias razones:

Con gran frecuencia las elecciones de las fuentes son poco originales. Los docentes pueden recibir el mismo pasaje copiado de una fuente popular por varios estudiantes.

A menudo es fácil determinar si un estudiante usó su propia «VOZ» ya que las expresiones son distintas a las que el emplea en su propio texto.

Los alumnos pueden escoger fuentes inapropiadas, inexactas o fuera del tema.

Para detectar un posible plagio, con ayuda de un motor de búsqueda se puede indagar una determinada cadena de palabras del texto sospechoso, con el fin de ver si se encuentra un texto potencialmente plagiado. En la actualidad existen varios programas informáticos que facilitan la detección de esta anormalidad, especialmente en proyectos o ensayos de los estudiantes.

Sin embargo el mayor medio para luchar contra el plagio son las mismas escuelas, universidades y casas de estudio, que frecuentemente no lo penalizan en sus reglamentos, 
incluso tratándose de tesis o proyectos terminales de titulación. Asimismo, usuarios de la red social Twitter han publicado acerca de una creciente cantidad de informes de plagio, que han identificado rápida y eficazmente.

En las universidades españolas no existen aún procedimientos intra-académicos de regulación del plagio entre personal docente e investigador. La vía habitual es presentar una queja ante la oficina del Defensor universitario y también a la inspección de servicios. En la mayoría de los Estatutos Universitarios no existe reconocimiento explícito en relación con posibles penalizaciones o valoraciones por un comité de expertos.

Pero debemos tener en cuenta que muchas veces se acusa de copia o plagio a los estudiantes y no es cierto. La línea que divide el plagio de las similitudes sospechosas es muy delgada, y siempre es posible alegar que los parecidos se deben a cuestiones culturales o históricas, a una inspiración compartida por el hecho de pertenecer a la misma época, por vivir en el mismo país.

En cualquier caso, la mera repetición de cadenas de palabras no es una prueba concluyente de deshonestidad intelectual. Gran parte del discurso científico es repetición de conocimientos (fórmulas, datos, etcétera) e hipótesis compartidas por la comunicad científica. Por ello se deberían evitar pronunciamientos apresurados sin un examen detallado de las posibles violaciones o suplantaciones de la autoría intelectual.

Los estudiantes ante la copia y el plagio

Es interesante ver la opinión de los estudiantes sobre el tema, que queda reflejada en una encuesta realizada en la universidad de Extremadura (Clemente, Gómez, González 2004):

Más del 50\% considera aceptable ir a un centro que elabora un trabajo y presentarlo como suyo. Más del $60 \%$ conoce a alguien que lo ha hecho y sin embargo menos de un $25 \%$ reconoce su autoría.

En estas situaciones se ve como aceptable, y además habitual, utilizar chuletas en los exámenes, y podemos concluir, según las respuestas obtenidas, que no se le da importancia a la propiedad intelectual.

Una de las razones mejor consideradas para hacer copias es la de establecer que el profesor no explica adecuadamente

La creencia de que las políticas en contra del fraude en la Universidad son severas, se presenta como el motivo más disuasorio; por ello este apartado de la encuesta ha sido uno de 
los más interesantes y determinantes en el comportamiento de los estudiantes. Si se establece una política severa sobre las copias y el plagio, quizás sea entendida como medida disuasoria para no copiar estas prácticas.

Los profesores, encuestados de manera informal, habían tenido más de un caso de fraude en sus asignaturas, y habían actuado suspendiendo al alumno. Todos los encuestados respondieron afirmativamente ante la creencia de que existe normativa sobre la práctica de fraude, y suponen que esta normativa incluye la apertura de un expediente sancionador e incluso la expulsión en caso de reincidencia. Estos profesores quedaron sorprendidos cuando les mencionamos que tal normativa no existía.

\section{Bibliografía y fuentes}

bibliotecaformacion/BECO/plagio.

biblioteca.ua.es/es/.../aprende-sobre-el-plagio-y-como-evitarlo.html

Celin Arce Gómez (2009). "Plagio y derechos de autor.” El Foro, № 10, págs. 59-67.

Jaume Sureda, Rubén Comas, Mercè Morey (2009). "Las causas del plagio académico entre el alumnado universitario según el profesorado”. Revista iberoamericana de educación. № 50 (2009), pp. 197-220.

Jiménez Soto, I. (2009). Derechos y deberes en la comunidad universitaria. Ed. Marcial Pons, Madrid.

Pedro J. Clemente, Alberto Gómez, Julia González (2004). La copia de prácticas de programación: el problema y su detección.

wikipedia.org/wiki/Plagio. 


\section{ANEXO I}

"Cuando el plagio llega al ninot indultado. Acusan el artista Pedro Abad de copiar una figura basada en el Laberinto del Fauno.”

Periódico INFORMACIÓN, 18.06.2014 | 15:56

Sin tiempo para reponerse de la denuncia suscitada por el plagio del secretario del Gremio de Artistas Falleros, ahora es un ilustrador quién exige una rectificación al presidente del Gremio de Constructores de Hogueras.

Moisés Domínguez | valencia «Exijo una disculpa pública por parte del señor Pedro Abad por la usurpación de mis legítimos derechos, de los que se está aprovechando y pretende beneficiarse en un concurso como ha sido lo de la Exposición del Ninot y el Concurso de Hogueras. Un concurso donde entiendo tiene que premiarse la originalidad y no la copia del trabajo de un compañero, y más siendo el máximo responsable de un colectivo cómo es el de Artistas Constructores de Hogueras de Alicante, emplazándolo que indico tanto en la propia hoguera y en lugar visible, como en el "ninot" recientemente indultado, quién es el autor original de la obra en que está inspirada su hoguera. Si no es así, me reservo todas las acciones legales que crea menester para defender mi trabajo» así de contundente fue ayer el ilustrador Sergio Sandoval acusando el artista Pedro Abad después de contrastar que el remate principal y el ninot indultado de la hoguera La Cerámica es, según su versión, una copia no autorizada de un dibujo suyo. Una polémica que enlaza con la suscitada hace dos semanas con el secretario del Gremio de Artistas Falleros, que firmó como propio un esbozo que había plagiado otro realizado por el diseñador Ramón Pla.

Invertir y quitar un libro.

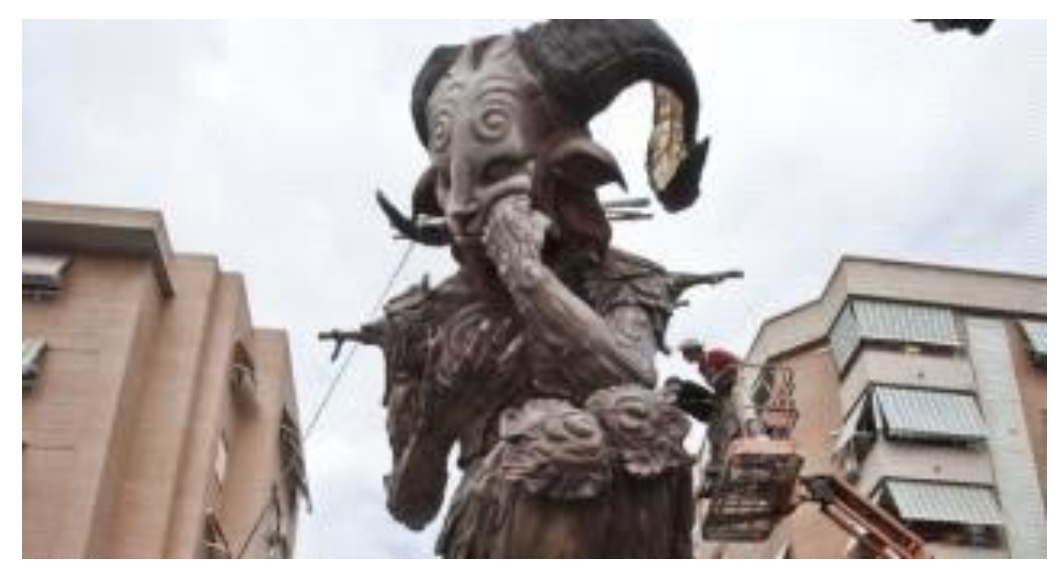


Sandoval acusa Abad de utilizar un dibujo realizado a un particular y que estaba basado en los figurines realizados por él mismo para la película «El laberinto del fauno». La indignación del ilustrador es mayor por el hecho que el dibujo se habría copiado "a pelo". «Ni siquiera se ha tomado la molestia de cambiar la mano con que el Fauno sostiene el libro, directamente se lo ha quitado y ha dejado la mano tal cual la dibujé yo. Además de esto, lo ha invertido y listo». La hoguera milita en la Sección Especial y ha sido, precisamente, la primera en ser izada en la plantá, que acaba de empezar en Alicante. 


\section{ANEXO II. \\ CASOS DE PLAGIO EN LA UNIVERSIDAD DE ALICANTE}

\begin{tabular}{|c|c|c|c|}
\hline PERÍODO & 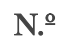 & RESUMEN & RESULTADO \\
\hline $2013 / 2014$ & 262 & $\begin{array}{l}\text { Estudiante. Acusado de plagio en } \\
\text { el TFM. Está suspendido }\end{array}$ & $\begin{array}{l}\text { El decano hace que otro profesor especialista realice } \\
\text { una nueva corrección. Se demuestra que hay muchas } \\
\text { páginas "copia y pega" de Internet. Se mantiene la } \\
\text { puntuación obtenida por el alumno. }\end{array}$ \\
\hline 2013/2014 & 241 & $\begin{array}{l}\text { Estudiante. La profesora de las } \\
\text { prácticas les acusa de plagio }\end{array}$ & $\begin{array}{l}\text { La profesora los llamó a tutoría, porque le parecía } \\
\text { imposible que ese trabajo lo hubieran realizado ellos } \\
\text { solos, puesto que a lo largo del proceso de trabajo en } \\
\text { relación con el mismo dentro del aula, no habían } \\
\text { presentado nada sobre el mismo. Comprobó, junto al } \\
\text { coordinador de la asignatura si había plagio, pero no } \\
\text { lo había. En la tutoría mantenida con los estudiantes, } \\
\text { el trabajo era realizado por cuatro personas, } \\
\text { confirmaron que parte del trabajo había sido } \\
\text { elaborado por una persona externa al grupo, por eso } \\
\text { mantiene una calificación de } 5 \text {. Su criterio fue poner } \\
\text { esa nota puesto que la evaluación de adquisición de } \\
\text { competencias de aprendizaje en relación con el } \\
\text { mismo, no han sido adquiridas por ellos. Los alumnos } \\
\text { insisten en que a pesar de que pidieron ayuda, el } \\
\text { trabajo lo realizaron ellos y quieren oportunidad de } \\
\text { demostrarlo. Llegado a una vía muerta se cierra el } \\
\text { tema. }\end{array}$ \\
\hline $2013 / 2014$ & 128 & $\begin{array}{l}\text { Estudiante. La asignatura consta } \\
\text { de tres partes, en el trabajo copió } \\
\text { sin citar al autor. La profesora le } \\
\text { ha puesto un cero en toda la } \\
\text { asignatura cuando la media de } \\
\text { las otras tres partes le da } \\
\text { aprobado. }\end{array}$ & $\begin{array}{l}\text { La profesora no cede y el director del departamento } \\
\text { La apoya fervientemente. Incluso elaboran un } \\
\text { documento para justificar su decisión que presentan } \\
\text { en la Oficina. }\end{array}$ \\
\hline $2013 / 2014$ & 169 & $\begin{array}{l}\text { Estudiante. Estaba haciendo un } \\
\text { examen y tenía el móvil en la silla } \\
\text { para controlar el tiempo, el } \\
\text { profesor le ha acusado de copiar. }\end{array}$ & Le ponen un 0. \\
\hline $2013 / 2014$ & 178 & $\begin{array}{l}\text { Actuación de oficio. Dos alumnos } \\
\text { de Selectividad ha sido pillados } \\
\text { "in Fraganti" pasándose datos } \\
\text { uno a otro en un examen. }\end{array}$ & $\begin{array}{l}\text { Se habla con el director del Secretariado de Acceso y } \\
\text { Promoción, pero éste señala el carácter de oposición } \\
\text { que presentan las PAU ya que la gente compite por } \\
\text { una plaza. Tienen un } 0 .\end{array}$ \\
\hline
\end{tabular}


54 Estudiantes. Tenían la misma modalidad de examen pero no se pasaron información, tiene varias contestaciones distintas y la pregunta de desarrollo también, se les acusa de copiar.

156 Estudiantes. Haciendo el examen, el profesor las cambió de sitio, una detrás de la otra; luego, sin que hicieran nada, al entregar el examen las puso juntas y dice que se han copiado. Les ha puesto un 0 .
Sobre la aplicación del principio de "presunción de inocencia” puesto que existía y existe, en mi opinión, "una duda razonable", unos indicios, no una mera sospecha, que podría desvirtuar tal principio constitucional. Están aprobados.

Enviado e-mail al profesor indicando que no puede suspenderlas por meras sospechas. Les repitió el examen, han aprobado. 